\title{
A Comparative Analysis of Environmental Quality Assessment Methods-a Case Study of Heavy Metal-Contaminated Soil
}

\author{
Zhichao Liu ${ }^{1,2, a}$, Liangmin Gao ${ }^{1, b,}$ Ning Liu $^{2,3, c}$ and Xiaoxiao Zhang ${ }^{2, d}$ \\ ${ }^{1}$ School of Earth and Environment, Anhui University of Science and Technology, Huainan 232001, \\ China \\ ${ }^{2}$ School of the Environment, Nanjing University, Nanjing 210023, China \\ ${ }^{3}$ School of Chemistry \& Life Science, Nanjing University Jinling College, Nanjing 210089, China \\ anjuliuzc@163.com, bgaolmin@163.com, cliuning@nju.edu.cn, d'shirleyzhang@nju.edu.cn
}

Keywords: environmental assessment; fuzzy mathematical model; pollution index method; heavy metal-contaminated soil; soil.

\begin{abstract}
Four assessment methods (two pollution index and two fuzzy mathematical models) were employed to investigate the environmental quality of eight soils around a heavy metal contaminated site. From the results of analysis, comprehensive index model is more reasonable compared with the single-factor index method; Compared with the pollution index, in fuzzy mathematical methods, membership functions were used to describe the limits between different pollution degrees, and different weights were allocated for the factors according to pollution contribution. In the single-factor deciding model, the dominant factor was given more attention, and the effects of the other factors were weakened. However, in the weighted average model, the contribution of each factor was well taken into account, and the weights were allocated for the factors according to the contribution degree. In fuzzy mathematical methods, membership functions were used to describe the limits between different pollution degrees, and different weights were allocated for the factors according to pollution contribution. Introduction of membership degree and weight of each factor to fuzzy mathematical models made the methods more reasonable in the field of environmental quality assessment.
\end{abstract}

\section{Introduction}

Soil is one of the most important and fundamental resources for human survival and development. In China, considerable amounts of heavy metals in soils have become an increasing issue for several years $^{[1-2]}$. The heavy metal contamination is partly due to emissions from metallurgical industries in various chemical forms during the smelting of non-ferrous metals. These potentially toxic elements accumulating in soils induce a potential contamination of food chain and endanger the ecosystem safety and human health ${ }^{[3]}$. Heavy metals contaminated soil has a character as hidden, hysteresis and cumulative ${ }^{[4]}$. Environmental quality assessment of heavy metal-contaminated soils not only discloses the effects of human activities on the soil environment, but also provides theoretical information for the sustainable development of the limited soil resource ${ }^{[5]}$.

Pollution index methods have been widely used to assess soil environmental quality. The methods employ definite limit to differentiate and quantify the extent of soil pollution ${ }^{[6]}$. However, in all environmental quality assessments, owing to inconsistency and peculiarities of each soil pollutant, there is a vagueness or fuzziness in relation to environmental risk. In classification schemes, fuzziness makes it difficult to justify the use of sharp boundaries. This fuzziness has led some environmental researchers to investigate advanced assessment methods based on fuzzy logic ${ }^{[7]}$. Fuzzy methods evaluate comprehensively the contributions of various pollutants according to predetermined weights, and decrease the fuzziness using membership functions. Fuzzy comprehensive assessment has been proved to be effective in solving problems of fuzzy boundaries and controlling the effect of monitoring errors on assessment results ${ }^{[8]}$. 
The objectives of this study were: i) to assess environmental risks of heavy metal pollution in the soils around a ferroalloy manufacturing plant using pollution index and fuzzy mathematical methods; and ii) to compare the assessment results to learn about the application characteristics of the assessment methods employed.

\section{Sampling and analyses}

Site overview. Mainly used for producing and operating sodium dichromate and chromic anhydride, the targeted contaminated site in this research is located at an industrial city in North China Plain. With a production history of over 20 years and a complete set of production facilities, the enterprise occupying nearly $33000 \mathrm{~m}^{2}$ lands with about $16000 \mathrm{~m}^{2}$ of usable space completely stopped production in 2008, and production equipment and buildings in this site have been all removed.

Relevant studies show that a lot of "three wastes" generated by the production activities of similar enterprises are discharged into the environment, probably bringing harm to the surroundings and accordingly polluting such environmental media as the peripheral soil and underground water, and as a result, such sites become typical heavy metal contaminated sites.

Sampling and analysis. On the basis of the investigation and analysis on the previous production history, raw materials, products, production process and pollution prevention and renovation measures regarding this site, a professional judgment method is adopted to set sampling points of maximum likelihood and representativeness for collecting topsoil samples and deep soil samples. Eight sampling points are set at the centers of different areas within the site, and after proper shifting and adjustment were conducted according to the actual structure situation, stratum structure and hydrogeological condition of this site. A total of eight soil samples, from 0 to $20 \mathrm{~cm}$ depth.

The soil samples contacting the metal sampling instrument during the process of sample selection in the field have been eradicated and then collected in $250 \mathrm{ml}$ glass bottle which is tightly plugged by a bottle cap with PTFE sealing gasket and then sealed by PTFE film. After natural withering in shady and cool ventilation environment, plant root system, organic residues and visible intrusive body are removed from the samples, and then the samples are grinded in mortar and screened by 10-mesh, 60-mesh and 100-mesh nylon screens. Finally, six typical heavy metal pollutants (As, Ni, Cr, Cu, Cd and $\mathrm{Zn}$ ) probably existing in this site are analyzed. Concentrations of $\mathrm{Zn}, \mathrm{Ni}, \mathrm{Cr}, \mathrm{Cu}$ and $\mathrm{Cd}$ were determined using ICP-MS. And As using an inductively coupled plasma spectrometer. The Excel software (Microsoft Co.) was used for statistical analyses of the data obtained in the experiments.

\section{Pollution index methods}

Calculation formulas of pollution index methods. Two pollution index methods (single-factor index method and Nemerow comprehensive index method) were employed to evaluate the environmental quality of the eight polluted soils. The calculation of the single-factor index method can be expressed as:

The calculation of the single-factor index method can be expressed as:

$P_{i}=\frac{C_{i}}{S_{i}}$

The mathematical formula of the Nemerow comprehensive index method is:

$$
P=\sqrt{\frac{\left(\frac{1}{n} \sum_{i=1}^{n} P_{i}\right)^{2}+\left(\operatorname{Max}\left(P_{i}\right)\right)^{2}}{2}}
$$

Where Pi is the pollution index of heavy metal $\mathrm{i}$; $\mathrm{Ci}$ is the actual monitoring data of heavy metal $\mathrm{i}$ (mg•kg-1); Si is the environmental quality standard, the data is sourced from Grade A standards specified in the Assessment Standards for Soil Environmental Quality of Exhibition Lands (Provisional) (HJ350-2007) (mg•kg-1)(Table1); P is the Nemerow comprehensive pollution index. 
Establishment of assessment criteria. The inorganic elements (Zn, As, Ni, Cr, $\mathrm{Cu}$ and $\mathrm{Cd}$ ) were selected to assess the environmental quality of the eight polluted soils. Assessment criteria were established based on the actual local situation and the National Environmental Quality Standards of China. The soil quality was classified on five levels: class I, excellent; class II, clean; class III, slightly polluted; class IV, moderately polluted; and class V, heavily polluted (Table 2).

Table. 1 Environmental quality standard for soil: (mg. kg-1)

\begin{tabular}{ccccccc}
\hline Heavy metal & $\mathrm{Zn}$ & $\mathrm{As}$ & $\mathrm{Ni}$ & $\mathrm{Cr}$ & $\mathrm{Cu}$ & $\mathrm{Cd}$ \\
\hline Evaluation standard & 200 & 20 & 50 & 190 & 63 & 1 \\
\hline
\end{tabular}

Table. 2 Environment quality classification for heavy metal contaminated soils

\begin{tabular}{cccccc}
\hline Heavy metal & $\begin{array}{c}\mathrm{I} \\
\text { (excellent } \\
\text { ) }\end{array}$ & $\begin{array}{c}\text { II } \\
\text { (clean) }\end{array}$ & $\begin{array}{c}\text { III } \\
\text { (slightly } \\
\text { polluted) }\end{array}$ & $\begin{array}{c}\text { IV } \\
\text { (moderately } \\
\text { polluted) }\end{array}$ & $\begin{array}{c}\text { V } \\
\text { (heavily } \\
\text { polluted) }\end{array}$ \\
\cline { 2 - 6 } Zn & 100 & 200 & 250 & 300 \\
$\mathrm{As}$ & 12 & 17 & 20 & 25 & 300 \\
$\mathrm{Ni}$ & 40 & 50 & 65 & 80 & 200 \\
$\mathrm{Cr}$ & 78 & 150 & 250 & 350 & 400 \\
$\mathrm{Cu}$ & 35 & 50 & 100 & 150 & 400 \\
$\mathrm{Cd}$ & 0.20 & 0.30 & 0.45 & 0.60 & 1.0 \\
Nemerow & & 0.70 & $1.00<\mathrm{P} \leq 1.70$ & $1.70<\mathrm{P} \leq 2.80$ & $\mathrm{P}>2.80$ \\
comprehensive & $\mathrm{P} \leq 0.70$ & $<\mathrm{P} \leq 1.00$ & & \\
index (P) & & & & \\
\hline
\end{tabular}

Assessment results of pollution index methods. According to the calculation of Eqs.1 and 2, the values of single-factor index and comprehensive pollution index were obtained based on actual heavy metal monitoring data ( $\mathrm{Ci}$ ) for the eight evaluated soils. Both $C_{i}$ values and assessment results are shown in Table 3.

\section{Fuzzy mathematical methods}

Establishment of membership functions for fuzzy environmental quality. Membership functions represent the degrees to which the specified concentration belongs to the Fuzzy set. The membership degrees of heavy metals at each level can be described quantitatively by a set of formulas of membership functions as follows:

$$
u_{i, m}=\left\{\begin{array}{cl}
1-u_{(m-1)}\left(C_{i}\right) & e(m-1) \leq C i \leq e(m) \\
{\left[e(m+1)-C_{i}\right] /[e(m+1)-e(m)],} & e(m) \leq C i \leq e(m+1) \\
0 & C i \geq e(m+1)
\end{array}\right.
$$

Where ui, $\mathrm{m}$ is the membership degree of heavy metal $\mathrm{i}$ at class $\mathrm{m}, \mathrm{Ci}$ is the actual monitoring data of heavy metal i in mg•kg-1, and e (m) is the criteria value at class $\mathrm{m}$ in $\mathrm{mg} \bullet \mathrm{kg}-1$.

After the monitoring data of each heavy metal at each area and the assessment criteria were substituted into the membership function, the fuzzy matrix was obtained for each assessed soil sample. For example, the fuzzy matrix of soil S1 $\left(R_{1}\right)$ was expressed as:

Determination of weight for each heavy metal. It is very important to choose the appropriate weight for each factor since the contribution to integrated environmental quality varies greatly among different heavy metals. The weight of each heavy metal at each monitoring area is allocated according to:

$$
W_{i, k}=\frac{C_{i, k} / S_{i}}{\sum_{i=1}^{n} C_{i, k} / S_{i}} \quad S_{i}=\frac{1}{n} \sum_{j=1}^{n} S_{i j}
$$




$$
R_{1}=\left|\begin{array}{ccccc}
1.00 & 0 & 0 & 0 & 0 \\
0 & 0.60 & 0.40 & 0 & 0 \\
1.00 & 0 & 0 & 0 & 0 \\
1.00 & 0 & 0 & 0 & 0 \\
1.00 & 0 & 0 & 0 & 0 \\
1.00 & 0 & 0 & 0 & 0
\end{array}\right|
$$

Table. 3 Environment quality assessment results for eight polluted soils using single factor index and comprehensive index methods

\begin{tabular}{|c|c|c|c|c|c|c|c|c|c|}
\hline \multirow[b]{2}{*}{ Soil } & \multirow[b]{2}{*}{ Index } & \multicolumn{6}{|c|}{ Heavy metal } & \multicolumn{2}{|c|}{ Environment quality } \\
\hline & & Zn & As & $\mathrm{Ni}$ & $\mathrm{Cr}$ & $\mathrm{Cu}$ & $\mathrm{Cd}$ & $\begin{array}{c}\text { Single-facto } \\
\text { r index }\end{array}$ & $\begin{array}{c}\text { Comprehensive } \\
\text { index }\end{array}$ \\
\hline \multirow{3}{*}{$\mathrm{S} 1$} & $\mathrm{Ci}$ & 76.60 & 18.20 & 26.20 & 67.90 & 21.10 & 0.01 & \multirow{3}{*}{ III } & \multirow{3}{*}{$\begin{array}{c}\mathrm{II} \\
(\mathrm{P}=0.71)\end{array}$} \\
\hline & $\mathrm{Pi}$ & 0.38 & 0.91 & 0.52 & 0.36 & 0.33 & 0.01 & & \\
\hline & Class & I & III & $\mathrm{I}$ & I & I & I & & \\
\hline \multirow{3}{*}{$\mathrm{S} 2$} & $\mathrm{Ci}$ & 77.10 & 7.40 & 35.60 & 88.10 & 29.10 & 0.02 & \multirow{3}{*}{ II } & \multirow{3}{*}{$\begin{array}{c}\mathrm{I} \\
(\mathrm{P}=0.58)\end{array}$} \\
\hline & $\mathrm{Pi}$ & 0.39 & 0.37 & 0.71 & 0.46 & 0.46 & 0.02 & & \\
\hline & Class & I & I & I & II & I & I & & \\
\hline \multirow{3}{*}{ S3 } & $\mathrm{Ci}$ & 67.80 & 12.80 & 28.40 & 86.70 & 25.10 & 0.02 & \multirow{3}{*}{ II } & \multirow{3}{*}{$\begin{array}{c}\mathrm{I} \\
(\mathrm{P}=0.53)\end{array}$} \\
\hline & $\mathrm{Pi}$ & 0.34 & 0.64 & 0.57 & 0.46 & 0.40 & 0.02 & & \\
\hline & Class & I & II & $\mathrm{I}$ & II & I & I & & \\
\hline \multirow{3}{*}{$\mathrm{S} 4$} & $\mathrm{Ci}$ & 89.80 & 10.80 & 20.50 & 220.00 & 23.60 & 0.03 & \multirow{3}{*}{ III } & \multirow{3}{*}{$\begin{array}{c}\mathrm{II} \\
(\mathrm{P}=0.89)\end{array}$} \\
\hline & $\mathrm{Pi}$ & 0.45 & 0.54 & 0.41 & 1.16 & 0.37 & 0.03 & & \\
\hline & Class & I & I & I & III & I & I & & \\
\hline \multirow{3}{*}{ S5 } & $\mathrm{Ci}$ & 69.80 & 10.70 & 30.30 & 2340.00 & 39.60 & 0.02 & \multirow{3}{*}{$\mathrm{V}$} & \multirow{3}{*}{$\begin{array}{c}\mathrm{V} \\
(\mathrm{P}=8.88)\end{array}$} \\
\hline & $\mathrm{Pi}$ & 0.35 & 0.54 & 0.61 & 12.32 & 0.63 & 0.02 & & \\
\hline & Class & I & I & I & V & II & I & & \\
\hline \multirow{3}{*}{ S6 } & $\mathrm{Ci}$ & 45.30 & 10.70 & 28.60 & 8640.00 & 36.00 & 0.02 & \multirow{3}{*}{ V } & \multirow{3}{*}{$\begin{array}{c}\mathrm{V} \\
(\mathrm{P}=32.63)\end{array}$} \\
\hline & $\mathrm{Pi}$ & 0.23 & 0.54 & 0.57 & 45.47 & 0.57 & 0.02 & & \\
\hline & Class & I & I & I & V & II & I & & \\
\hline \multirow{3}{*}{ S7 } & $\mathrm{Ci}$ & 96.40 & 7.80 & 21.50 & 52500.00 & 109.00 & 0.03 & \multirow{3}{*}{$\mathrm{V}$} & \multirow{3}{*}{$\begin{array}{c}\mathrm{V} \\
(\mathrm{P}=198.03)\end{array}$} \\
\hline & Pi & 0.48 & 0.39 & 0.43 & 276.32 & 1.73 & 0.03 & & \\
\hline & Class & I & I & I & V & IV & I & & \\
\hline \multirow{3}{*}{ S8 } & $\mathrm{Ci}$ & 76.50 & 10.10 & 28.50 & 90.20 & 30.40 & 0.01 & \multirow{3}{*}{ II } & \multirow{3}{*}{$\begin{array}{c}\mathrm{I} \\
(\mathrm{P}=0.49)\end{array}$} \\
\hline & Pi & 0.38 & 0.51 & 0.57 & 0.47 & 0.48 & 0.01 & & \\
\hline & Class & I & I & I & II & I & I & & \\
\hline
\end{tabular}

Where WI, $\mathrm{k}$ indicates the weight of heavy metal $\mathrm{i}$ at soil $\mathrm{k}, \mathrm{Ci}, \mathrm{k}$ is the monitoring concentration of heavy metal i at soil $\mathrm{k}$ in mg•kg-1, Si is the average assessment criteria of heavy metal i in mg•kg-1; and $\mathrm{Si}, \mathrm{j}$ is the criteria value of heavy metal $\mathrm{i}$ at class $\mathrm{j}$ in mg・kg-1.

In this paper, the weights were selected based on both the soil quality assessment criteria and the actual monitoring data. Here, $C_{i, k}$ indicated the extent of exceeding the average assessment criterion since it was assumed that this included the difference among the pollutant elements and the pollution degree.

According to Eq. 4, the weights of the six heavy metals in the eight assessed soils were achieved and are given in Table 4.

Assessment results of fuzzy mathematical methods. The environmental quality of the eight polluted soils were assessed using two fuzzy mathematical methods: single-factor deciding and weighted average model. Calculation of single-factor deciding model is performed according to: 
Table. 4 Weights of heavy metals in the assessed soils

\begin{tabular}{ccccccc}
\hline Soil & $\mathrm{Zn}$ & $\mathrm{As}$ & $\mathrm{Ni}$ & $\mathrm{Cr}$ & $\mathrm{Cu}$ & $\mathrm{Cd}$ \\
\hline S1 & 0.15 & 0.46 & 0.16 & 0.15 & 0.07 & 0.01 \\
S2 & 0.17 & 0.22 & 0.25 & 0.22 & 0.12 & 0.02 \\
S3 & 0.14 & 0.35 & 0.19 & 0.20 & 0.10 & 0.02 \\
S4 & 0.15 & 0.24 & 0.11 & 0.41 & 0.07 & 0.03 \\
S5 & 0.02 & 0.05 & 0.03 & 0.87 & 0.02 & 0.01 \\
S6 & 0.005 & 0.01 & 0.01 & 0.96 & 0.01 & 0.005 \\
S7 & 0.002 & 0.002 & 0.001 & 0.99 & 0.003 & 0.002 \\
S8 & 0.17 & 0.29 & 0.19 & 0.22 & 0.12 & 0.01 \\
\hline$b=M a x$ & $\{W$
\end{tabular}

$b_{j}=\operatorname{Max}\left\{W_{1} u_{1 \mathrm{j}}, W_{2} u_{2 \mathrm{j}}, \cdots, W_{n} u_{\mathrm{nj}}\right\}$

And the weighted average model can then be expressed as:

$b_{j}=\sum_{i=1}^{n} W_{i} u_{i j}$

Where bj is the membership degree of final assessment result at class $\mathrm{j}$, WI indicates the weight of heavy metal $\mathrm{i}$ at the assessed area, and ui, $\mathrm{j}$ is the membership degree of heavy metal $\mathrm{i}$ at class $\mathrm{j}$.

The assessment vectors of the single-factor deciding model were normalized before application of the results to assess the environmental quality for the eight polluted soils. While the evaluation vector of weighted average model do not need processing normalization. According to Eqs.5 and 6, the final assessment results of the two fuzzy mathematical methods were achieved for the soil samples (Table 5).

\section{Result and discussion}

Comparison between the two pollution index methods. As seen in Table II, the assessment result of single-factor index method for the eight soils were class III, II, II, III, V, V, V and II, which was determined according to the principle of maximum membership grade. However, through the comprehensive index method, the environmental quality of the eight soils were identified to be classes II, I, I, II, V, V, V and I, respectively. The evaluation result is determined by Nemerow comprehensive index $\mathrm{P}$, it not only takes the maximum pollution index into account, also considered the average pollution index.

From the above results, it is demonstrated that the soil environmental qualities identified with single-factor index method were worse than those of the comprehensive index model. The distinction of the assessment principle between the two methods resulted in the different values. Only the maximum contributing factors were introduced into the single-factor index method, and other factors were neglected in the assessment. Thereby, in practical assessment work, it is usually found that the factors with high concentration (heavily polluted) have a fateful influence on the final assessment results obtained by the single-factor method. However, the dominant parameter and the average contribution of all factors were both taken into account for the comprehensive index method used in the present research, and a better environmental quality was achieved as the assessment result ${ }^{[9]}$. The difference mentioned above between the two pollution index methods can be further proved by the application example of the models given in Table 5. Therefore, compared with the single factor index method, the comprehensive index method is more reasonable.

Comparison between the two fuzzy mathematical methods. As seen in Table 5, the two fuzzy mathematical methods have a different environmental evaluation result for soil heavy metals pollution, which because of the difference of the membership degree to each pollution class existed between the two methods. Differences is that the environment quality evaluate result of weighted average model may be superior to the single-factor deciding model. The difference between the assessment results was attributed to the distinct assessment objectives and principle. Single-factor deciding model, in fact, only consider the most prominent factor, the effect of other factors is weakened. So in the case analysis, mainly reflects the influence of the higher relative 
content and serious pollution condition of evaluation factors on the evaluation results. While the weighted average model fully consider each factor's contribution to the comprehensive evaluation, and distribute the contribution by the weights, the evaluation result is the product of each contestant indexes combination ${ }^{[10]}$. Such as S4, caused by the interference of high relative content of Cr, the evaluation result of single-factor deciding model is III, but when using the weighted average model to evaluate, the evaluation results is $\mathrm{I}$.

Table. 5 Final membership degrees of fuzzy mathematical methods at five levels for the eight polluted soils

\begin{tabular}{ccccccccc}
\hline & \multicolumn{9}{c}{ Single-factor deciding model } & & & \\
Soil & S1 & S2 & S3 & S4 & S5 & S6 & S7 & S8 \\
\hline I & 0.26 & 0.89 & 0.84 & 0.37 & 0.05 & 0.01 & 0.01 & 0.89 \\
II & 0.45 & 0.11 & 0.16 & 0.19 & 0.01 & 0.00 & 0.00 & 0.11 \\
III & 0.29 & 0.00 & 0.00 & 0.44 & 0.00 & 0.00 & 0.00 & 0.00 \\
IV & 0.00 & 0.00 & 0.00 & 0.00 & 0.00 & 0.00 & 0.00 & 0.00 \\
V & 0.00 & 0.00 & 0.00 & 0.00 & 0.94 & 0.99 & 0.99 & 0.00 \\
Environmental quality & II & I & I & III & V & V & V & I \\
\hline Soil & Weighted & Sverage model & & & & \\
I & 0.54 & 0.97 & 0.92 & 0.59 & 0.12 & 0.04 & 0.01 & 0.96 \\
II & 0.28 & 0.03 & 0.08 & 0.12 & 0.01 & 0.00 & 0.00 & 0.04 \\
III & 0.18 & 0.00 & 0.00 & 0.29 & 0.00 & 0.00 & 0.00 & 0.00 \\
IV & 0.00 & 0.00 & 0.00 & 0.00 & 0.00 & 0.00 & 0.00 & 0.00 \\
V & 0.00 & 0.00 & 0.00 & 0.00 & 0.87 & 0.96 & 0.99 & 0.00 \\
Environmental quality & I & I & I & I & V & V & V & I \\
\hline
\end{tabular}

Like the relationship between the two pollution index methods, the environmental quality obtained by the weighted average model was slightly better than that obtained by the single-factor deciding method. The application example of the two fuzzy mathematical methods (Table 5) can be a better proof to support the conclusion. The difference between the assessment results was attributed to the distinct assessment objectives and principle ${ }^{[11]}$. In the single-factor deciding model, the dominant factor was given more attention, and the effects of the other factors were weakened. However, in the weighted average model, the contribution of each factor was well taken into account, and the weights were allocated for the factors according to the contribution degree; therefore, the assessment results of the weighted average model were dependent on the integrated effects of all factors to a great extent.

Comparison between pollution index and fuzzy mathematical methods. According to the results in Tables II and IV, the assessment results of environmental quality were evaluated to be better by fuzzy mathematical models, whereas pollution index methods made the results worse. In the later methods, a simple number was marked as a limit to differentiate two distinct grades of pollution degree. Such as the concentration of the heavy metal $\mathrm{Cr}$ in S2 is $86.7 \mathrm{mg} \cdot \mathrm{kg}^{-1}$, and the two closest environmental criteria values were 78 (class I) and $150 \mathrm{mg} \cdot \mathrm{kg}^{-1}$ (class II). It is obvious that 86.7 is closer to 78 instead of 150 , but with the pollution index method , the environmental quality of soil S2 was determined to be class II. In fuzzy methods, fuzziness logic makes it difficult to justify the use of criteria's sharp boundaries. Membership functions were employed to describe the limit between different pollution degrees. The 86.7 membership of 86.7 to 78 is 0.86 , and to 150 is 0.14 , which demonstrates that class I, not class II is more reasonable to be assigned to the level of environmental risk caused by $\mathrm{Cr}$ pollution at soil S2. Similarly, metal Cu in S6 evaluated class II also does not conform to the actual level, should be rated as class I.

At the same time, different from pollution index methods, fuzzy mathematical ways were established with more attention paid to the contribution of all factors to the integrated pollution ${ }^{[12]}$. Different weights were allocated for different factors, and the weight reflected the contributing capacity of each factor. For example, according to contribution degrees, the 
pollutants in soil S4 were listed in the following sequence: $\mathrm{Cr}>\mathrm{As}>\mathrm{Zn}>\mathrm{Ni}>\mathrm{Cu}>\mathrm{Cd}$ (Table 4). The fuzzy mathematical methods that introduce weight to environmental assessment are more reasonable than the pollution index models in the field of environmental quality assessment.

The single-factor methods (including single-factor index and single-factor deciding models) are applicable in the situation where individual evaluation factor is over proof and the assessment aim is to externalize the principle of single factor rejection. However, the comprehensive methods (including Nemerow pollution index and weighted average models) are applicable in the situation where the contents of evaluation factors are even and the evaluation aim is to externalize the contribution of each factor to the soil environmental quality. Therefore, in practical work, it is necessary to select a suitable model according to monitoring data and assessment objectives to make the assessment results satisfactory to practical requirements and close to the facts.

\section{Conclusions}

Pollution index and fuzzy mathematical methods were employed to investigate the environmental quality of eight soils (soils S1-S8) contaminated by heavy metals. The assessment result of the single-factor index method were classes III, II, II, III, V, V, V and II for soils S1-S8, while the results of the comprehensive index model were classes II, I, I, II, V, V, V and I, respectively. In comparison with the single-factor index method, the comprehensive index model concerned both dominant parameter and average contribution of all factors to the integrated environmental quality.

In the two fuzzy mathematical methods (single-factor deciding and weighted average models), w i th single-factor deciding method the environmental qualities were identified to classes II, I, I, III, $\mathrm{V}, \mathrm{V}, \mathrm{V}$ and I, while the results of weighted average model were classes I, I, I, I, V, V, V and I, respectively, The difference of the membership degree to each pollution level occurred between the two methods. The environmental qualities obtained by the weighted average model were slightly better than those of the single-factor deciding method in this research. The divergence resulted from the different assessment objectives and principles of the two fuzzy methods.

In the pollution index method, the environmental quality can be divided into several grades with sharp boundaries, while in the fuzzy mathematical method, fuzziness makes it difficult to identify the use of the criteria's sharp boundaries. Membership functions were used to describe the limit between different pollution degrees, and different weights were allocated for the factors according to their pollution contribution in the fuzzy mathematical methods. Compared with the present methods, fuzzy mathematical models were more reasonable for environmental risk assessment owing to the introduction of membership degree and weight of each factor to the models.

\section{References}

[1] Cheng, S. P. Heavy metal pollution in China: Origin, pattern and control, J. Environmental Science and Pollution Research. 10(3) ( 2003) 192-198. (in chinese)

[2] Zhao, Q. G. Land resources, mother earth-Protection, construction and sustainable utilization of the land resources of China, issues that deserve high attention, J. Soils. 36(4) (2004) 337-339. (in chinese)

[3] K. Shah, and J. M. Nongkynrih, Metal hyperaccumulation and bioremediation, J. Biologia Plantarum. 51(4) (2007) 618-634.

[4] Liu, D, M, Sun, H, Fang, Z, L. Retrospet and prospect research of soil environmental quality, J. Sichuan Environment. 28(1) (2009) 73-77. (in chinese)

[5] J. Jensen, and M. B. Pedersen, Ecological risk assessment of contaminated soil, J. Reviews of Environmental Contamination and Toxicology. 186(2006) 73-105. 
[6] He, T., Liao, B. H., Zeng, M., Lei, et al. Investigation on arsenic pollution of paddy fields in 4 mining areas in southern Hunan, J. Asian Journal of Ecotoxicology. 2(4)(2007) 470-475.

[7] B.Fisher, Fuzzy environmental decision-making: applications to air pollution, J. Atmospheric Environment, 37(2003) 1865-1877.

[8] Wang, H. Y. Assessment and prediction of overall environmental quality of Zhuzhou City, Hunan Province, China, J. Journal of Environmental Management. 66(2002) 329-340.

[9] S. Mishra, S. Bhalke, I. V. Saradhi, et al. Trace metals and organometals in selected marine species and preliminary risk assessment to human beings in Thane Creek area, Mumbai, J. Chemosphere. 69(6) (2007) 972-978.

[10] J.Geldermann, T. Spengler, O. Rentz, Fuzzy outranking for environmental assessment. Case study: iron and steel making industry, J. Fuzzy Sets and Systems. 115(2000) 45-65.

[11] Chang, N. B., K. R. Srilakshmi and G. Parvathinathan, Comparison of models of simazine transport and fate in the subsurface environment in a citrus farm , J. Journal of Environmental Management. 86(1) (2008) 27-43.

[12] Li, J. B., Liu, L., Huang, G. H. M. et al. A fuzzy-set approach for addressing uncertainties in risk assessment of hydrocarbon-contaminated site, J. Water, Air, and Soil Pollution. 171(1-4) ( 2006) 5-18. 